\title{
Propaganda, a arte de gerar descrédito
}

\author{
Armando Levy Maman \\ Especialista em Gestão da Comunicação e Mestre em Teoria e Pesquisa em Comunicação \\ pela Escola de Comunicações e Artes da USP. \\ E-mail: armando@epress.com.br
}

Resumo: Este estudo busca evidenciar o desgaste de imagem sofrido pela Credicard S.A., empresa de serviços financeiros, em função de investimentos maciços em propaganda. Levei a proposta de análise dessa questão ao curso de especialização em Gestão da Comunicação, da Escola de Comunicação e Artes da USP, o qual me daria o aparato teórico necessário para pensar o problema e propor-lhe uma solução. Analisaram-se cartas de reclamações de clientes enviadas a jornais e revistas, em comparação com a comunicação praticada pela empresa para vender seus serviços. Seis anos depois, esse estudo se transformaria no livro Propaganda, a arte de gerar descrédito, publicado pela Editora da Fundação Getúlio Vargas.

Palavras-Chave: propaganda de massa, imagem corporativa, cartas de reclamação, imprensa.
Abstract: This study tries to evidence the damages in the image of Credicard SA, financial services company, because of its massive investiments in advertisement. I presented this proposal of analysis to the specialization course in Communication Management, offered in Escola de Comunicações e Artes of USP, which would give me the necessary theoretical aparatus to think this issue and propose a solution. We analysed client complaint letters sent to newspapers and magazines in comparison with communication practiced by the corporation to sell its services. Six years later, this study would become the book "Advertising, the art of generating discredit", published by Editora da Fundação Getúlio Vargas.

Keywords: mass advertising, corporate image, complaint letters, press.

Em 1993, a Credicard S.A., criada pelos bancos Itaú, Unibanco e Citibank 24 anos antes, era a empresa líder no segmento de cartões de crédito no Brasil. Com seis milhões de clientes, 41 bancos associados e milhares de estabelecimentos filiados, a empresa exibia um faturamento global anual de US\$ 12 bilhões, dos quais aproximadamente US\$ 300 milhões transformavam-se em lucro para seus acionistas. No entanto, por trás dessa força e magnificência, a empresa exibia uma fragilidade que a levaria à extinção em 2005, quando os acionistas resolveram fechá-la: a perda acentuada de clientes.

O que tornava este fenômeno ainda mais interessante era o fato de que a empresa acumulava uma perda de 2 milhões de clientes em seis anos, a despeito de investimentos maciços em propaganda, que superavam a cifra de $\mathrm{R} \$ 700$ milhões no mesmo período. Anúncios em revistas como Exame, Veja e IstoÉ, em 
comunicação \& educação • Ano XIII • Número 3 • set/dez 2008

redes de televisão como Globo, Bandeirantes e Record, além de jornais como Folha de S. Paulo, Estado de S. Paulo e Gazeta Mercantil, não pareciam ajudar a empresa a superar um problema que poucos na organização conseguiam entender: o crescente cancelamento de cartões.

Em 1993, o fotógrafo da Bennetton, Oliviero Toscani, veio ao Brasil debater seu livro A publicidade é um cadáver que nos sorri, que seria lançado no Brasil dois anos depois ${ }^{1}$. Ele enfrentou o publicitário Francesc Petit, da agência de propaganda DPZ, uma das três agências da Credicard, em um debate promovido pela TV Cultura. Petit, que chegou a esmurrar a mesa e vociferar contra o fotógrafo, acusava Toscani de demagogo e esforçava-se em defender a propaganda. Toscani ria e ridicularizava o publicitário brasileiro, acusando de ser um vendedor de ilusões e de se apropriar de milhões de seus clientes sem dar realmente nada em troca.

Aquele debate chamou minha atenção para a necessidade de entender o que realmente se passava com os investimentos em propaganda da empresa onde eu era assessor de imprensa. Levei a proposta de análise dessa questão ao curso de especialização em Gestão da Comunicação da Escola de Comunicação e Artes da USP e, seis anos depois, esse estudo se transformaria no livro Propaganda, a arte de gerar descrédito, publicado pela Editora da Fundação Getúlio Vargas. O curso me daria o aparato teórico necessário para pensar o problema e propor-lhe uma solução.

\section{ANÁLISE DE CONTEÚDO}

Para examinar os efeitos da propaganda de massa praticada pela empresa em seus próprios negócios, desenvolvi uma análise de conteúdo de dois tipos de comunicação:

1) A comunicação que chegava do cliente para a companhia, através de cartas com reclamações contra a empresa, endereçadas a colunas de defesa do consumidor de grandes jornais; e

2) A comunicação que saía da empresa para o cliente, por meio de peças publicitárias produzidas e veiculadas pelas agências de propaganda da empresa.

1. TOSCANI, Oliviero. A publicidade é um cadáver que nos sorri. Rio de Janeiro: Ediouro, 1996. 
Propaganda, a arte de gerar descrédito - Armando Levy Maman

QuADRO I - Jornais que receberam as cartas de clientes da Credicard S.A.

\begin{tabular}{|l|c|c|}
\hline Veículo & Cartas recebidas & $\%$ do total \\
\hline O Globo - RJ & 36 & 39,56 \\
\hline O Estado de S. Paulo - SP & 19 & 20,88 \\
\hline Folha de S. Paulo - SP & 17 & 18,69 \\
\hline Jornal da Tarde - SP & 08 & 8,80 \\
\hline O Dia - RJ & 05 & 5,50 \\
\hline Diário Popular - SP & 03 & 3,30 \\
\hline Jornal de Santa Catarina - SC & 01 & 1,09 \\
\hline Procon - SP & 01 & 1,09 \\
\hline Correio Popular - SP & 01 & 1,09 \\
\hline Total & 91 & 100 \\
\hline
\end{tabular}

Oito jornais e uma instituição de defesa do consumidor concentraram o recebimento de todas as 91 cartas enviadas pelos clientes da empresa contendo reclamações no período analisado. A análise de conteúdo das cartas permitiu visualizar quais problemas levaram aqueles clientes a se manifestar publicamente contra a empresa.

\section{Quadro II - Problemas apontados pelos clientes da Credicard S.A. nas cartas aos jornais}

\begin{tabular}{|l|c|c|}
\hline Queixa & Citaçães & $\%$ do total \\
\hline Cobrança por produto não adquirido & 11 & 12 \\
\hline Envio da fatura com atraso & 10 & 11 \\
\hline Produto recusado nas lojas & 10 & 11 \\
\hline Erro no documento de cobrança & 09 & 10 \\
\hline Pediu produto, pagou e não recebeu & 09 & 10 \\
\hline Cobrança por compra não efetuada & 07 & 8 \\
\hline Pediu produto, mas produto foi negado & 06 & 7 \\
\hline Aceitou oferta de produto, mas produto foi negado & 05 & 6 \\
\hline 12 outras queixas & 24 & 25 \\
\hline Total de queixas: 20 & 91 & 100 \\
\hline
\end{tabular}

Entre as 91 cartas, surgiram exatos 20 questionamentos específicos, o que revelava a repetição de problemas. A pesquisa procurou identificar, em um segundo passo, os adjetivos utilizados pelos clientes para classificar a empresa.

QUADRO III - Adjetivos utilizados pelos clientes para qualificar a empresa

\begin{tabular}{|l|c|}
\hline Adjetivos usados pelos clientes & Quantas vezes foi citado \\
\hline Desrespeitosa & 08 \\
\hline Incompetente & 08 \\
\hline Negligente & 06 \\
\hline Omissa & 06 \\
\hline Ineficiente & 05 \\
\hline Arrogante & 04 \\
\hline Não é transparente & 04 \\
\hline Confusa & 04 \\
\hline Inacessível & 04 \\
\hline Desleixada & 03 \\
\hline Decepcionante & 03 \\
\hline Outros 29 adjetivos & 39 \\
\hline Total: 40 adjetivos & Citados 94 vezes \\
\hline
\end{tabular}


Em 91 cartas surgem 40 adjetivos, citados 94 vezes. Além destes, surgiram outros, que apareceram em menor número de vezes, mas eram indicativos cristalinos de como o cliente via a empresa: máquina, ladra, usurária e variações. Foi dessa forma que os clientes que recorreram aos jornais para difundir suas queixas enxergavam a empresa na qual confiaram quando adquiriram o produto. E não acreditavam mais. E pior: era dessa forma que eles queriam que o mundo visse a empresa.

Pode-se argumentar que se tratava apenas de 91 queixas em um universo de 6 milhões de clientes; no entanto, como veremos adiante no quadro com as razões da demanda ao serviço de atendimento telefônico, é evidente que a amostra era apenas a ponta de um iceberg. De modo geral, os autores daquelas 91 cartas eram pessoas instruídas, usavam a linguagem escrita com fluência, criavam uma narrativa com começo, meio e fim para explicar uma situação e buscavam evidenciar, ao máximo, as falhas que tiveram que suportar da empresa.

\section{IMPACTO NEGATIVO NA IMAGEM}

Para completar a análise das cartas, buscou-se compreender o público potencial das cartas efetivamente publicadas. É evidente que, quando um leitor envia uma carta ou e-mail ao jornal, ele espera sua publicação. Anseia por isso não só para conseguir uma solução para seu problema, como, também, para alertar outras pessoas e, assim, punir a empresa que o tratou mal, fazendo-a perder clientes. Por isso, este dado é relevante.

QUADRO IV - Leitores por carta efetivamente publicada

\begin{tabular}{|c|c|c|c|}
\hline Veículo & $\begin{array}{l}\text { Cartas recebidas e } \\
\text { remetidas à empresa }\end{array}$ & Cartas publicadas & $\begin{array}{l}\text { Leitores por } \\
\left.\text { edição }{ }^{(* *}\right)\end{array}$ \\
\hline Jornal da Tarde & 08 & 06 & 88.000 \\
\hline Folha de S. Paulo & 17 & 05 & 450.000 \\
\hline O Globo & 36 & 04 & 350.000 \\
\hline O Estado de S. Paulo & 19 & 04 & 350.000 \\
\hline Diário Popular & 03 & $04\left(^{*}\right)$ & 140.000 \\
\hline O Dia & 05 & 03 & 290.000 \\
\hline A Crítica - PA & 00 & $02\left(^{*}\right)$ & 56.000 \\
\hline Revista Exame & 00 & $02\left(^{*}\right)$ & 171.000 \\
\hline Gazeta do Povo & 00 & $02\left(^{*}\right)$ & 56.000 \\
\hline Folha da Tarde & 00 & $01\left(^{\star}\right)$ & 120.000 \\
\hline Jornal do Comércio & 00 & $01\left(^{*}\right)$ & 42.000 \\
\hline Jornal de Brasília & 00 & $01\left(^{*}\right)$ & 23.000 \\
\hline Correio Braziliense & 00 & $01\left(^{*}\right)$ & 53.000 \\
\hline Jornal de Santa Catarina & 01 & 00 & $20.000(* \star)$ \\
\hline Correio Popular & 01 & 00 & $45.000\left(^{(* \star \star)}\right.$ \\
\hline Procon & 01 & 00 & 0 \\
\hline Total: 16 veículos & 91 & 36 & 7,8 milhões $(* \star \star \star)$ \\
\hline
\end{tabular}

* Publicou mais cartas do que recebeu no período por duas razões: a) Tinha cartas pendentes a publicar ou b) Publicou carta não remetida à empresa.

** Segundo dados do Instituto de Verificação de Circulação (IVC), em junho de 1996.

*** Circulação não computada no cálculo final, porque o jornal não publicou a carta recebida.

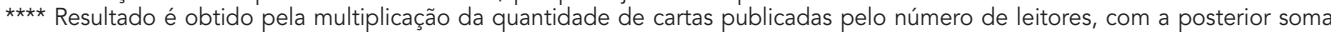
do resultado, porque as cartas não foram publicadas no mesmo dia. 
Ao constatar esses dados, em 1996, me fiz a seguinte pergunta, que ficou registrada no livro: "De que forma uma empresa pode sobreviver, a longo prazo, com semelhante grau de exposição negativa?”. Em 2005, a resposta ficou evidente, pois a Credicard foi extinta por seus acionistas, que dividiram sua base de clientes.

\section{A VOZ DA EMPRESA}

Para entender o posicionamento da empresa, foi realizada uma análise de conteúdo da propaganda produzida e distribuída pelas agências de propaganda contratadas pela companhia, também no período de janeiro a junho de 1996. O foco na comunicação escrita, representada por anúncios em jornais e revistas, não significava ignorar a comunicação eletrônica, concebida por anúncios em rádio e televisão, porque, em essência, a comunicação da empresa era bastante padronizada, integrando os conteúdos de ambas as comunicações, e utilizando a primeira com o objetivo de sustentar e ratificar a segunda. Nas peças publicitárias analisadas, foram destacados os adjetivos que a empresa usava para definir a si mesma, buscando, dessa forma, confrontar estes com aqueles outros enumerados pelos clientes insatisfeitos.

QUADRO V - Adjetivos que a empresa usa para qualificar a si mesma

\begin{tabular}{|l|c|}
\hline Como a empresa se vê & Vezes em que aparece \\
\hline Líder & 12 \\
\hline Aberta & 07 \\
\hline Múltipla & 07 \\
\hline Receptiva & 07 \\
\hline Mais aceita & 07 \\
\hline Econômica & 07 \\
\hline Racional & 07 \\
\hline Idealista & 07 \\
\hline Poupadora & 06 \\
\hline Facilitadora & 06 \\
\hline Provedora & 05 \\
\hline Liberdade de Escolha & 05 \\
\hline Prática & 05 \\
\hline Outros 12 adjetivos & 17 \\
\hline Total: 25 adjetivos & Usados 105 vezes \\
\hline
\end{tabular}

Olhando este painel de adjetivos, estamos diante da empresa perfeita. Tratase de uma companhia líder, que afirma isso repetidas vezes. E liderança significa ter o maior número de adeptos de todo o mercado. Mas significa muito mais: denota deter poder e as condições necessárias para atender os seguidores da empresa em todas as suas necessidades. Ser líder quer dizer ter sido eleita pela maioria para o desempenho de uma missão. Note que a empresa utilizou 25 adjetivos, repetidos 105 vezes, o que demonstra que, numa só peça publicitária, vários desses adjetivos eram citados de forma combinada. 


$$
\text { comunicação \& educação • Ano XIII • Número } 3 \text { • set/dez } 2008
$$

O dado mais perturbador revelado por este quadro não é o fato de ficar evidente o quanto tal comunicação é absurda e patética. Incômodo, mesmo, é perceber que as agências de propaganda, que criam coisas como estas, e as empresas, que pagam por elas, acreditam que este tipo de comunicação só tem um efeito, que é o de gerar vendas. Essas empresas não se questionam, nem por um segundo, se existe uma enorme possibilidade de o consumidor acreditar, de fato, nesta comunicação irreal e esperar pela sua concretização. Mas o que acontece quando a comunicação que gerou a venda se revela uma mentira?

\section{VOZES DISSONANTES}

Compare os quadros de adjetivos: o dos clientes, para definir a empresa, e o da empresa, para definir a si mesma. A empresa se dizia Líder. O consumidor frustrado apontava-a como Desrespeitosa. São fatos que retratam situações absolutamente antagônicas: uma empresa que busca vender uma imagem de perfeição e um grupo de clientes que se frustrou com essa imagem.

Mensalmente, a área de Atendimento a Clientes da "Líder S.A." elaborava um gráfico contendo as razões que levavam os clientes a contatar a companhia por telefone. O gráfico de junho de 1996 dizia mais ou menos o seguinte:

\section{QuADRO VI - Razões da demanda ao Serviço de Atendimento a Clientes}

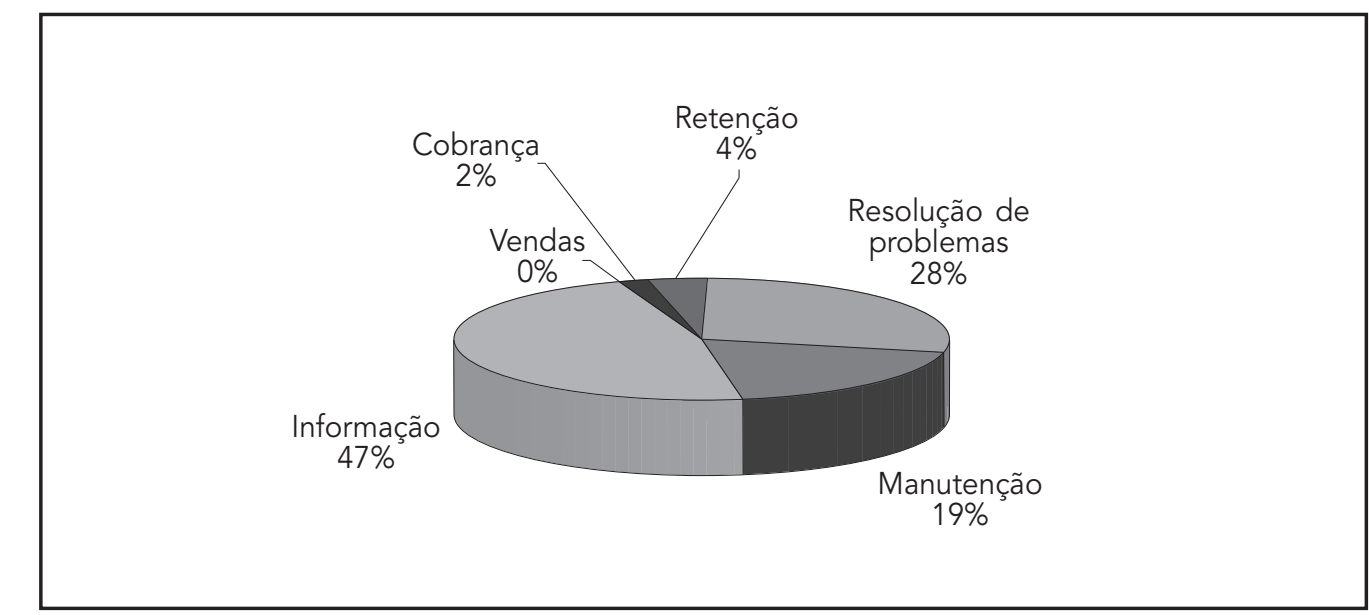

Fonte: Atendimento a Clientes da Credicard S.A. - 06/96.

Para compreender melhor esse quadro, estamos falando de pouco mais de 1 milhão de ligações telefônicas de consumidores. Desse total, $28 \%$ estavam reportando problemas com os produtos que compraram, especialmente atraso na entrega do boleto para pagamento e cobranças por bens não adquiridos; exatamente as mesmas reclamações apontadas nas cartas dos clientes aos jornais. Ou seja: em termos gerais, é correto imaginar que uma fração dos problemas solucionados ou não neste ponto tende a se transformar em cartas aos jornais. Note que, de 1 milhão de clientes que ligaram, $4 \%$ foram classificados no item retenção. Isso significa que eles manifestaram desejo de devolver o produto 
adquirido. Ao fazerem isso, tiveram suas ligações direcionadas para uma área específica, com pessoal preparado, que buscava evitar essa devolução. Ou seja: apenas em junho de 1996, mais de 42 mil pessoas pretendiam se livrar do produto da empresa. Isto talvez explique o fato de que, em 2005, a Credicard S.A. tenha sido extinta por seus acionistas em função de baixa lucratividade. Tratava-se de um desfecho que poderia ter sido previsto dez anos antes.

\section{POR UMA NOVA COMUNICAÇÃO EMPRESARIAL}

O uso massivo do discurso da propaganda é marcadamente autoritário. Esse tipo de discurso cria uma contradição insuperável: a organização empresarial, cada vez mais vista pela sociedade como uma instituição política, engendrada com o objetivo de atender a demandas específicas, assume perante o público o papel de uma instituição que tem um fim em si mesma, orientada apenas para o lucro a qualquer preço, sem nenhuma responsabilidade para com o conjunto da sociedade. Além disso, ao basear sua comunicação com o público no uso massivo da propaganda, as organizações empresariais forjam a instrumentalização dos meios de comunicação de massa, levando-os a prestar um péssimo serviço à sociedade e às próprias empresas.

De acordo com Habermas ${ }^{2}$, o uso da ação comunicativa como base do poder na sociedade eliminaria o caráter de dominação inerente às atuais estruturas sociais, as quais se perpetuam através do uso da razão instrumental. A ação comunicativa poderia mover o centro de poder na direção da sociedade. Habermas imagina que o resultado da mudança de uma sociedade baseada na razão instrumental para outra baseada na ação comunicativa poderia ser bastante positivo para a sociedade, que continuaria a produzir e a vender, mas garantiria melhores empregos e maior renda para a população. Para o mundo empresarial, a proposta de Habermas pode ser traduzida em uma frase: "Deixem o cliente falar e escutem o que ele tem a dizer".

Segundo este autor, há um choque entre a razão instrumental, aquela do mundo sistêmico (econômico), ou seja, quando o sujeito do conhecimento toma a decisão de que conhecer é dominar e controlar a natureza e os seres humanos, e a razão comunicativa, aquela que emana do mundo vivido (cultura). Esse choque tem-se revelado prejudicial ao desenvolvimento do ser humano enquanto ser racional, e desastroso também para as organizações empresariais, que investem quantidades astronômicas de dinheiro em campanhas publicitárias duvidosas, que, na maioria dos casos, resultam em algum crescimento de vendas acompanhado de aumento da distorção da imagem e da perda de clientes.

O Projeto de Gestão desenvolvido após essas análises e com base nessa visão crítica da publicidade previa uma comunicação mais pessoal e transparente da empresa com seus consumidores, sem o instrumentalismo e o imediatismo que costumam regê-la e que poucos resultados proporcionam, como diagnosticou a pesquisa levada a efeito. Infelizmente, tais propostas nem sempre são aceitas
2. HABERMAS, Jürgen Teoria de la acción comunicativa (Teoria da ação comunicativa). Madrid: Taurus, 1987 
comunicação \& educação • Ano XIII • Número 3 • set/dez 2008

ou reconhecidas a tempo. De qualquer forma, gestão da comunicação pressupõe uma nova postura do gestor diante dos recursos existentes na mídia e na própria empresa.

\section{REFERÊNCIAS BIBLIOGRÁFICAS}

ADORNO, Theodor W. A indústria cultural. In: Comunicação e indústria cultural. São Paulo: Companhia Editora Nacional, 1978.

BARROS FILHO, Clóvis de. Ética na comunicação: da informação ao receptor. São Paulo: Moderna, 1995.

BAUDRILLARD, Jean. Le système des objets. In: Teoria da cultura de massa. São Paulo: Paz e Terra, 1990.

CHANLAT, Jean-François. Ciências sociais e management. São Paulo: Atlas, 2000.

CITELLI, Adilson. Linguagem e persuasão. São Paulo: Ática, 1995.

CLEGG, Stewart. Modern organizations. Newbury Park (USA): Sage, 1991.

DUAILIBI, Roberto; SIMONSEN JR., Harry. Criatividade em marketing. São Paulo: McGraw-Hill, 1990.

EDWARDS, Elwin. Introdução à teoria da informação. São Paulo: Cultrix, 1971.

FIGUEIREDO, Luiz Celso de Piratininga. As imagens que a vida não prepara e a arte publicitária cria. In: Anuário de inovações em comunicações e artes. São Paulo: ECA/USP, 1989.

FREIRE, Paulo. A importância do ato de ler. São Paulo: Cortez, 1985.

. Pedagogia do oprimido. São Paulo: Paz e Terra, 1983.

FREITAG, Barbara. A teoria crítica ontem e hoje. São Paulo: Brasiliense, 1993.

HABERMAS, Jürgen. Comunicação, opinião pública e poder. In: Comunicação e indústria cultural. São Paulo: Companhia Editora Nacional, 1978.

. Teoria de la acción comunicativa (Teoria da ação comunicativa). Madrid: Taurus, 1987.

IANNI, Octavio. Enigmas da modernidade-mundo. Rio de Janeiro: Civilização Brasileira, 2000.

KIENTZ, Albert. Comunicação de massa: análise de conteúdo. Rio de Janeiro: Eldorado, 1973.

KOTLER, Philip. Marketing: edição compacta. São Paulo: Atlas, 1987.

LIMA, Luiz Costa (Org.). Teoria da cultura de massa. São Paulo: Paz e Terra, 1990.

LOPES, Maria Immacolata Vassallo de. Pesquisa em comunicação. São Paulo: Loyola, 1992. 
LUCE, Louise Fiber; SMITH, Elise (Eds.). Toward internationalism (Em direção ao internacionalismo). Cambridge: Newbury House, 1986.

McKENNA, Regis. Consumer Marketing Strategies (Estratégias de marketing de consumo). Boston: Harvard Business Review, 1991.

MORGAN, Gareth. Images of organization (Imagens de organização). Newbury Park (USA): Sage, 1986.

Creative organization theory (Teoria de organização criativa). Newbury Park (USA): Sage, 1989.

PETIT, Francesc. Propaganda ilimitada. São Paulo: Siciliano, 1991.

RAPP, Stan; COLLINS, Tom. Quinta geração do marketing. São Paulo: McGrawHill, 1991.

RIES, Al; TROUT, Jack. Marketing de guerra. São Paulo: Makron Books, 1989.

ROBERTS, Jeremy. Joseph Goebbels: nazi propaganda minister. Holocaust biographies (Joseph Goebbels: Ministro da propaganda nazista. Biografias do Holocausto). New York: Rosen Publishing Group, 2000.

SCHAFF, Adam. Linguagem e conhecimento. Coimbra: Almedina, 1976.

SIMÕES, Roberto Porto. Relações públicas: função política. São Paulo: Summus, 1995.

TAVARES, Maria das Graças de Pinho. Cultura organizacional. Rio de Janeiro: QualityMark, 1991.

THIOLLENT, Michel J. M. Crítica metodológica, investigação social e enquete operária. São Paulo: Polis, 1980.

TORQUATO, Francisco Gaudêncio. Comunicação empresarial: comunicação institucional. São Paulo: Summus, 1986.

Francisco Gaudêncio: cultura, poder, comunicação e imagem. São Paulo: Pioneira, 1991.

TOSCANI, Oliviero. A publicidade é um cadáver que nos sorri. Rio de Janeiro: Ediouro, 1996.

TRINDADE, Hélgio. Tentativa de reconstituição empírica de um movimento político radical. In: A aventura sociológica. Rio de Janeiro: Zahar, 1978.

VALENTE, Célia; NORI, Walter. Portas abertas. São Paulo: Best Seller, 1990.

WUTHNOW, Robert. Cultural Analysis (Análise cultural). London: Routledge, 1994. 